\title{
PERENCANAAN ULANG TATA LETAK FASILITAS PRODUKSI DENGAN METODE ALGORITMA CRAFT
}

\author{
Sahroni $^{*}$
}

\begin{abstract}
The PT. ERATEX DJAJA. Tbk. Probolinggo, on the weaving department had often the material disturbance and return flow of the moving material doe to the position of the department isn't suitable, so that needs arrangement the layout and production facilities that efficient and flexibility in the weaving department to avoid of the backtracking that can added the length of the moving distance of material, so that will drop down the productivity.

Arrangement and production facilities layout arrangement using CRAFT algorithm method to know the activity of production process from part one to another part, include the moving distance of handling material frequency. Compare the suggestion layout with the fist layout, then can to determine the advantage layout by the base method.

From the analysis we can know on the suggestion layout have long distance $10,82 \%$ concerning fist layout. Backtracking of the material handling occur 6 time, there are reducing $15,86 \%$ from the fist layout. The moving cost efficiency $2,05 \%$ occur fist layout
\end{abstract}

Key Word: Lay - out, material Handling, Implimention Cost

\section{A. PENDAHULUAN}

Tata letak (layout) atau pengaturan dari fasilitas produksi dan area kerja yang ada merupakan landasan utama dalam dunia industri. Pada umumnya tata letak pabrik yang terencana dengan baik akan ikut menentukan efisiensi dan dalam beberapa hal akan juga menjaga kelangsungan hidup ataupun kesuksesan kerja suatu industri.

Tujuan dari tata letak pabrik adalah mengurangungi perpindahan material, penjadwalan produksi secara lebih efektif dan segera mungkin memenuhi pesanan lebih tepat waktu dengan jalan menekan delay/idle time dan menjaga kelancaran aliran proses produksi. Kelancaran aliran proses produksi tersebut merupakan faktor utama yang sangat berpengaruh terhadap efisiensi dan produktifitas produksi perusahaan. Kelancaran proses produksi sangat dipengaruhi oleh beberapa faktor salah satunya adalah tata letak atau tata cara pengaturan fasilitas-fasilitas fisik perusahaan. Pengaturan fasilitas-fasilitas produksi yang tepat diharapkan mampu memanfaatkan luas tempat permesinan dan fasilitas lainnya serta memeperlancar gerakan perpindahan material sehingga diperoleh aliran proses kerja yang lancar, teratur dan aman.

Kondisi tersebut terjadi pada PT. Eratex djaja LTD. Tbk di departemen weaving yang menghasilkan produk kain grey. Dari pengamatan aliran produksinya khususnya weaving sering terjadi kemacetan material dan aliran balik dan pemindahan bahan yang disebabkan posisi departemen yang kurang tepat penempatannya, oleh karena itu diperlukan pengaturan dan penataan layout dan fasilitas-fasilitas produksi y7ang efisien dan fleksibel dalam departemen weaving untuk menghindari backtracking yang berakibat bertambah panjangnya jarak

*) Staff PT Philips 
perpindahan bahan sehingga akan menurunkan produktifitas produksi.

\section{B. LANDASAN TEORI}

Definisi Perencanaan dan Pengaturan Tata Letak Pabrik.

Tata letak pabrik (plant layout) atau Tata letak fasilitas (facilities layout) dapat didefinisikan sebagai tatacara pengaturan fasilitas-fasilitas pabrik guna menunjang kelancaran proses produksi.

Karena aktivitas produksi suatu industri secara normalnya harus berlangsung lama dengan tata letak yang tidak selalu berubah-ubah, maka setiap kekeliruan yang dibuat didalam perencanaan tata letak ini akan menyebabkan kerugian-kerugian yang tidak kecil. Tujuan utama didalam desain tata letak pabrik pada dasarnya adalah untuk meminimalkan total biaya

Selain itu pengaturan tata letak pabrik yang optimal akan dapat pula memberikan kemudahan didalam proses supervise serta menghadapi rencana perluasan pabrik dimasa akan datang.

\section{Tujuan perencanaan dan Pengaturan Tata Letak}

\section{Pabrik.}

Secara garis besar tujuan utama dari tata letak pabrik adalah mengatur area kerja dan segala fasilitas produksi yang paling ekonomis untuk operasi produksi aman, dan nyaman sehingga akan dapat menaikkan moral kerja dan performance dari operator.

\section{Algoritma Craft.}

CRAFT yang merupakan singkatan dari Computerized Relative Allocation Facilities Technique pertama kali diperkenalkan pada Armour, Buff, dan Vollman (1964). CRAFT merupakan salah satu algoritma pertama dalam literature. CRAFT menggunakan from to chart sebagai inputan. Biaya layout ditentukan berdasarkan jarak centroid. Departemen tidak dibatasi dalam bentuk rectangular.

CRAFT merupakan algoritma improvement sehingga memerlukan initial layout yang bisa merupakan layout dari departemen yang sudah ada atau hasil dari algoritma lain.

Secara umum CRAFT cukup fleksibel dalam bentuk departemen. Selama tidak terpisah CRAFT dapat mengakomodasi hampir semua bentuk departemen.

1. CRAFT dibatasi oleh bentuk bangunan rectangular. Tetapi dengan bantuaan "dummy" yang di-set fixed (tidak dapat dipindah), maka bentuk bangunan yang tidak beraturanpun dapat digunakan.

Salah satu kelebihan CRAFT adalah dapat mengakomodasi bentuk bangunan yang tidak beraturan secara presisi dengan adanya departemen "dummy". Tetapi kelemahan lain selain path-dependent hasil akhir yang didapat cenderung adalah bentuk departemen yang kotak dan lorong yang luas. Dengan menetapkan beberapa departemen dalam lokasi tertentu dan menggunakan departemen "dummy" dapat menghasilkan bentuk departemen yang lebih baik. Sebagai hasil akhir dari komputer sebaiknya layout akhir harus dilakukan perbaikan secara manual oleh perancang layout. 


\section{METODE}

Metode pengumpulan data yang digunakan antara lain :

1. Metode Penelitiaan lapangan (Field Research). Adapun teknik yang digunakan :

a. Observasi.

b. Wawancara (Interview)

2. Metode Study Kepustakaan (Library Research).

\section{Sumber Data.}

1. Data primer

Data yang diperoleh langsung dari subjek penelitiaan dengan menggunakan alat pengukuran atau alat pengambilan data langsung pada subjek sebagai sumber informasi yang dicari.

2. Data sekunder

Data yang diperoleh oleh pihak lain, tidak langsung diperoleh oleh peneliti dari subjek penelitiaan

\section{Langkah-langkah Penelitiaan.}

alam penelitian ini langkah-langkah yang di tempuh adalah :

1. Survey Perusahaan

Survey perusahaan dimaksudkan untuk mendapatkan informasi yang lebih kongkret tentang masalah-masalah yang dihadapi perusahaan.

2. Identifikasi Masalah

Identifikasi masalah ini dimaksudkan untuk mempelajari lebih detail terhadap permasalahan yang akan dijadikan tema/objek dari pelaksanaan penelitian.

3. Studi Literatur
Studi Literatur akan dipakai sebagai pedoman dalam menganalisa dan mencari solusi dari permasalahan.

4. Pengumpulan Data.

Mengumpulkan data dan informasi yang diperlukan untuk menyelesaikan permasalahan layout yang ada.

5. Pembuatan From to Chart

Yaitu pembahasan mengenei volume material yang dipindahkan dan aliran bahannya serta pembuatan travel chart atau from to chart dari aliran bahan yang terjadi pada proses produksi.

6. Pengolahan Dengan Menggunakan QS (Quantitative System).

Pada tahap ini untuk menganalisa datadata yang telah diperoleh

7. Perancangan Layout Usulan Hasil Program QS.

Tahapan selanjutnya adalah pembuatan layout usulan berdasarkan lay-out yang total contribusinya paling kecil.

8. Perhitungan Jarak dan Biaya Material Handling.

9. Analisa Hasil.

Dilakukan analisa perbandingan antara layout usulan dengan layout lama

10. Kesimpulan dan Saran.

merupakan rangkuman berdasarkan hasil analisa pemecahan masalah yang kemudiaan memberikan solusi perencanaan tata letak pabrik yang baru yang dapat meminimasi jarak perpindahan bahan. 


\section{ANALISA}

\section{Prinsip - prinsip dasar Perencanaan dan Pengaturan Tata letak Pabrik}

Berdasarkan aspek dasar, tujuan dan keuntungan-keuntungan yang bisa didapatkan dalam tata letak pabrik yang terencanakan dengan baik, maka bisa disimpulkan enam tujuan dasar dalam tata letak pabrik, yaitu sebagai berikut :

1. Integrasi secara menyeluruh dari semua faktor yang mempengaruhi proses produksi.

2. Perpindahan jarak yang seminimal mungkin.

3. Aliran kerja berlangsung secara lancar melalui pabrik.

4. Semua area yang dimanfaatkan secara efektif dan efisien.

5. Kepuasan kerja dan rasa aman dari pekerja dijaga sebaik-baiknya.

6. Pengaturan tata letak harus cukup fleksibel.

Tujuan dari perencanaan dan pengaturan tata letak pabrik dinyatakan sebagai prinsip dasar dari proses perencanaan tata letak pabrik yang selanjutnya dapat dijelaskan sebagai berikut :

1. Prinsip integrasi secara total.

Menyatakan bahwa tata letak pabrik adalah merupakan integrasi secara total dari seluruh elemen produksi yang ada menjadi satu unit operasi yang besar.

2. Prinsip jarak perpindahan bahan yang paling minimal.

Dalam proses pemindahan bahan dari satu operasi ke operasi yang lain, waktu dapat dihemat dengan cara mengurangi jarak perpindahan tersebut. Hal ini bisa dilaksanakan dengan cara mencoba menerapkan operasi yang berikutnya sedekat mungkin dengan operasi yang sebelumnya.
3. Prinsip aliran dari suatu proses kerja.

Prinsip ini mengusahakan untuk menghindari adanya gerakan balik (backtracking), gerakan memotong (crossmovement), kemacetan (congestion), dan sedapat mungkin material bergerak terus tanpa ada interupsi. Ide dasar dari prinsip aliran kerja ini adalah aliran konstan dengan minimum interupsi, kesimpangsiuran, dan kemacetan.

4. Prinsip pemanfaatan ruangan.

Prinsip ini menyatakan bahwa pada dasarnya tata letak adalah suatu pengaturan ruangan yaitu pengaturan ruangan yang dipakai manusia, bahan baku, mesin, dan peralatan penunjang proses produksi lainnya.

5. Prinsip kepuasan dan keselamatan kerja. Prinsip ini menyatakan bahwa tata letak yang baik adalah tata letak yang mampu menciptakan suasana kerja yang menyenangkan dan memuaskan, sehingga akan diperoleh keuntungan-keuntungan, diantarnya yaitu moral kerja yang lebih baik, mengurangi ongkos produksi, keselamatan kerja karyawan yang lebih terjamin.

6. Prinsip fleksibilitas.

Prinsip ini menyatakan bahwa tata letak pabrik harus cukup fleksibel untuk diadakan penyesuaian atau pengaturan kembali (re-layout) sehingga layout yang baru dapat dibuat dengan cepat dan murah.

(Sritomo Wignjosoebroto, $2000: 72$ ) 


\section{Analisa Lay-out Usulan}

Luas masing-masing departemen, dengan asumsi bahwa departemen yang tidak beraturan (tidak segi empat) dipotong menjadi beberapa bagian adalah sebagai berikut :

Tabel 1.

Luas Masing-Masing Departemen

\begin{tabular}{|c|c|c|}
\hline Departemen & Luas Area (me & eter) \\
\hline A & $27 \times 10$ & $=270$ \\
\hline B & $8 \times 12$ & $=96$ \\
\hline $\mathrm{C}$ & $26 \times 12$ & $=312$ \\
\hline D & $22 \times 12$ & $=64$ \\
\hline E & $32 \times 3,75$ & $=120$ \\
\hline \multirow[t]{2}{*}{$\mathrm{F}$} & $32 \times 11,25$ & $=360$ \\
\hline & $10 \times 12$ & $=120$ \\
\hline G & $32 \times 5$ & $=160$ \\
\hline $\mathrm{H}$ & $26 \times 16$ & $=416$ \\
\hline I & $9,85 \times 26$ & $=266$ \\
\hline J & $6,15 \times 26$ & $=160$ \\
\hline K & $60 \times 64$ & $=3840$ \\
\hline L & $32 \times 18$ & $=576$ \\
\hline M & $64 \times 24$ & $=1536$ \\
\hline $\mathrm{N}$ & $10 \times 50$ & $=500$ \\
\hline $\mathrm{O}$ & $5 \times 50$ & $=250$ \\
\hline \multirow[t]{2}{*}{ P } & $16 \times 35$ & $=350$ \\
\hline & $10 \times 28$ & $=280$ \\
\hline Q & $10 \times 35$ & $=350$ \\
\hline \multirow[t]{2}{*}{$\mathrm{R}$} & $3 \times 38$ & $=114$ \\
\hline & $7 \times 26,56$ & $=186$ \\
\hline \multirow[t]{2}{*}{ S } & $13 \times 31,54$ & $=410$ \\
\hline & $15 \times 10$ & $=150$ \\
\hline $\mathrm{T}$ & $36 \times 61$ & $=2196$ \\
\hline
\end{tabular}

Tabel 2.

Peralatan Dan Mesin Produksi

\begin{tabular}{|l|c|}
\hline \multicolumn{1}{|c|}{ Jenis Mesin } & Jumlah \\
\hline Warping. & 2 \\
Sizing. & 2 \\
Tenun Repair. & 18 \\
Tenun Jet Loom. & 76 \\
Tenun Projectile. & 149 \\
Cloth Inspection & 40 \\
Folding & 6 \\
Packing & 3 \\
Rolling & 2 \\
\hline
\end{tabular}

Tabel 3.

Analisa Jarak material andling

\begin{tabular}{|c|c|c|c|}
\hline $\begin{array}{c}\text { Hub. } \\
\text { aliran } \\
\text { pemin- } \\
\text { dahan }\end{array}$ & $\begin{array}{c}\text { Jarak } \\
\text { perpin- } \\
\text { dahan } \\
\text { antar } \\
\text { dept }\end{array}$ & $\begin{array}{c}\text { Frek. } \\
\text { Perpin- } \\
\text { dahan }\end{array}$ & $\begin{array}{c}\text { Jarak } \\
\text { tempuh }\end{array}$ \\
\hline A-G & 96 & 791 & 75936 \\
G-F & 14,9 & 791 & 11785,9 \\
F-E & 10,2 & 50 & 510 \\
F-C & 41,3 & 117 & 4832,1 \\
F-J & 64 & 8 & 512 \\
E-D & 20,6 & 50 & 1030 \\
C-D & 26 & 117 & 3042 \\
D-B & 45 & 167 & 7515 \\
B-H & 33 & 167 & 5511 \\
H-I & 15,1 & 167 & 2521,7 \\
I-K & 55,64 & 127 & 7066,28 \\
I-L & 100,9 & 40 & 4036 \\
K-M & 73,26 & 95 & 6959,7 \\
K-O & 86,18 & 32 & 2757,76 \\
L-M & 28 & 30 & 840 \\
L-O & 37 & 10 & 370 \\
M-N & 7 & 125 & 875 \\
O-N & 24 & 42 & 1008 \\
N-P & 35 & 167 & 5845 \\
P-Q & 20,9 & 107 & 2236,3 \\
P-R & 37,15 & 60 & 2256 \\
R-S & 55,83 & 60 & 3276,6 \\
Q-S & 26,8 & 107 & 2867,6 \\
S-T & 180,4 & 56 & 10102,4 \\
\hline & & Total & $\mathbf{1 6 3 6 9 2 , 3 4}$ \\
\hline
\end{tabular}

Tabel 4.

Jarak Antar Departemen

\begin{tabular}{|c|c|c|c|}
\hline $\begin{array}{l}\text { Hubungan } \\
\text { aliran } \\
\text { pemindahan }\end{array}$ & $\begin{array}{c}\text { Jarak } \\
\text { perpindahan } \\
\text { antar } \\
\text { departemen }\end{array}$ & $\begin{array}{l}\text { Frekuensi } \\
\text { Perpindahan }\end{array}$ & $\begin{array}{c}\text { Jarak } \\
\text { tempuh }\end{array}$ \\
\hline$A-G$ & 96 & 791 & 75936 \\
\hline$G-F$ & 8 & 791 & 6328 \\
\hline$F-E$ & 22 & 50 & 1100 \\
\hline $\mathrm{F}-\mathrm{C}$ & 43 & 117 & 5031 \\
\hline$F-J$ & 46 & 8 & 368 \\
\hline$E-D$ & 16 & 50 & 800 \\
\hline$C-D$ & 26 & 117 & 3042 \\
\hline$D-B$ & 16 & 167 & 7515 \\
\hline $\mathrm{B}-\mathrm{H}$ & 33 & 167 & 5511 \\
\hline $\mathrm{H}-\mathrm{I}$ & 25 & 167 & 4175 \\
\hline$I-K$ & 97.87 & 127 & 12429.49 \\
\hline$I-L$ & 101 & 40 & 4040 \\
\hline $\mathrm{K}-\mathrm{M}$ & 217.87 & 95 & 20697.65 \\
\hline $\mathrm{K}-\mathrm{O}$ & 202.87 & 32 & 6491.84 \\
\hline$L-M$ & 19 & 30 & 570 \\
\hline
\end{tabular}




\begin{tabular}{|c|c|c|c|}
\hline $\mathrm{L}-\mathrm{O}$ & 73 & 10 & 730 \\
$\mathrm{M}-\mathrm{N}$ & 7 & 125 & 875 \\
$\mathrm{O}-\mathrm{N}$ & 51 & 42 & 2142 \\
$\mathrm{~N}-\mathrm{P}$ & 19 & 167 & 3173 \\
$\mathrm{P}-\mathrm{Q}$ & 28 & 107 & 2996 \\
$\mathrm{P}-\mathrm{R}$ & 32 & 60 & 1920 \\
$\mathrm{R}-\mathrm{S}$ & 46 & 60 & 2760 \\
$\mathrm{Q}-\mathrm{S}$ & 19 & 107 & 2033 \\
$\mathrm{~S}-\mathrm{T}$ & 230 & 56 & 12880 \\
\hline \multicolumn{4}{|c|}{ Total }
\end{tabular}

\section{LAYOUT USULAN}

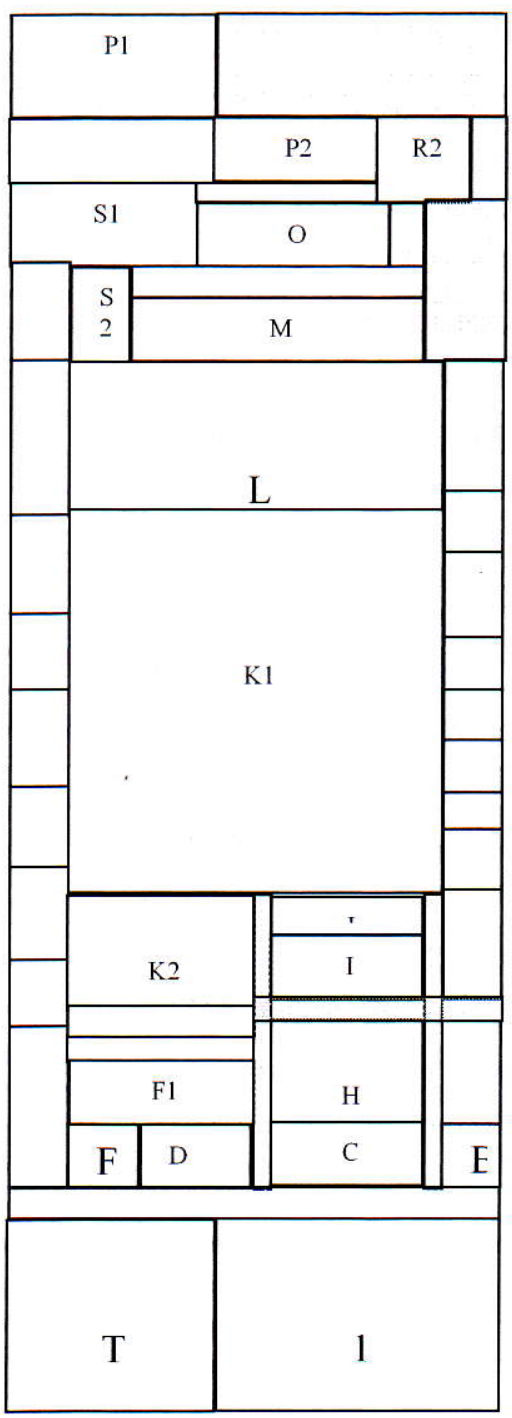

\section{Perhitungan From TO Chart}

Langkah-langkah awal dari from to chart adalah menyusun data mengenai $\%$ of Volume Handling dari data-data yang telah ada. Perhitungan \% of Volume Handling untuk A-G yaitu :

$\%$ of Volume Handling

$$
\begin{aligned}
& =\frac{\text { jumlahyangdipindahkan }(\mathrm{Kg})}{\text { Jumlahtotalyangdipindahkan }(\mathrm{Kg})} \times 100 \% \\
& =\frac{34393,14 \mathrm{Kg}}{1.062 .054,81} \times 100 \% \\
& =3,23 \%
\end{aligned}
$$

\section{Perancangan Lay-out Usulan}

Input data yang harus dimasukkan adalah :

1. Jumlah dan nama departemen,position departemen bisa dirubah atau tidak.

2. Layout awal yang menunjukkan panjang, lebar dan posisi tiap departemen.

3. Jumlah perpindahan Material antar departemen dalam bentuk From to Chart.

4. Biaya perpindahan per unit.

\section{Analisa Jarak material Handling}

$$
\begin{aligned}
\text { Jarak E-D } & =\left|\mathrm{X}_{E}-\mathrm{X}_{D}\right|+\left|\mathrm{Y}_{E}-\mathrm{Y}_{D}\right| \\
& =|25-41|+|59-59| \\
& =16
\end{aligned}
$$

Dengan cara yang sama dapat diketahui jarak material handling lainnya.

\section{Analisa Biaya Material Handling}

Dilakukan dengan cara yang sama seperti pada analisa biaya material handling pada layout awal, pada tabel berikut juga akan dianalisa biaya material handling layout usulan dengan memperhatikan hal-hal sebagai berikut:

1. kereta dorong : biaya material handling Rp. 145,45. 
2. Operator : biaya material handling Rp. 698,65

3. Forklif : biaya material handling Rp. 64,6

\section{Perbandingan Jarak Material Handling}

Dari hasil pengukuran jarak pemindahan bahan (material handling) layout awal dan layout usulan dapat diketahui perbandingannya seperti tabel berikut ini :

Tabel 5.

Hasil Pengukuran Jarak Pemindahan Bahan (Material Handling)

\begin{tabular}{|c|c|c|}
\hline layout awal & $\begin{array}{c}\text { Layout } \\
\text { Usulan }\end{array}$ & Selisih \\
\hline 183543,98 & 163692,34 & 19851,64 \\
\hline
\end{tabular}

Dari hasil perbandingan biaya material handling pada layout awal dan layout usulan dapat diketahui perbandingannya seperti yang terdapat pada tabel berikut :

Tabel 6.

Perbandingan Biaya material Handling

\begin{tabular}{|c|c|c|}
\hline $\begin{array}{c}\text { layout awal } \\
(\mathbf{R p})\end{array}$ & $\begin{array}{c}\text { layout } \\
\text { usulan (Rp) }\end{array}$ & $\begin{array}{c}\text { Selisih } \\
(\mathbf{R p})\end{array}$ \\
\hline $32.782 .605,5$ & $32.110 .746,8$ & $671.858,7$ \\
\hline
\end{tabular}

\section{Analisa Back Tracking}

\section{Back Tracking Pada Layout Awal}

Pada layout awal terdapat aliran balik atau back tracking pada proses aliran bahan yaitu

- Pada aliran proses dari departemen D (sizing) ke departemen B (stock beam sizing).

- Pada aliran proses dari departemen E (stock beam warping) ke departemen $\quad \mathrm{D}$ (sizing).

- Pada aliran proses dari departemen F (warping) ke departemen $\mathrm{E}$ (stock beam warping).

- Pada aliran proses dari departemen F (warping) ke departemen $\mathrm{C}$ (stock beam warping).
- Pada aliran proses dari departemen G (tempat penyimpanan benang) ke departemen F (warping).

- Pada aliran proses dari departemen O (Cloth Inspecting) ke departemen $\mathrm{N}$ (Folding).

Tabel 7.

Jarak Back Tracking Layout Awal

\begin{tabular}{|c|c|}
\hline Proses Produksi & Back Tracking (m) \\
\hline - $\quad \mathrm{D}-\mathrm{B}$ & 45 \\
\hline - $\quad E-D$ & 16 \\
\hline - $\quad \mathrm{F}-\mathrm{C}$ & 43 \\
\hline - $\quad F-E$ & 22 \\
\hline - $\quad \mathrm{G}-\mathrm{F}$ & 8 \\
\hline - $\quad \mathrm{O}-\mathrm{N}$ & 51 \\
\hline Total & $185 \mathrm{~m}$ \\
\hline
\end{tabular}

pembuatan kain CC 1088 V3/R, C 1296 V3/R, CC 5001 V6/J pada layout awal perusahaan terjadi 6 kali dengan jarak back tracking 185 meter

\section{Back Tracking Pada Layout Usulan}

Pada layout usulan terdapat aliran balik atau back tracking pada proses aliran bahan yaitu

- Pada aliran proses dari departemen D (sizing) ke departemen B (stock beam sizing).

- Pada aliran proses dari departemen E (stock beam warping) ke departemen D (sizing).

- Pada aliran proses dari departemen F (warping) ke departemen E (stock beam warping).

- Pada aliran proses dari departemen F (warping) ke departemen C (stock beam warping). 
- Pada aliran proses dari departemen G (tempat penyimpanan benang) ke departemen $\mathrm{F}$ (warping).

- Pada aliran proses dari departemen O (Cloth Inspecting) ke departemen N (Folding).

Tabel 7.

Jarak Back Tracking Layout Usulan

\begin{tabular}{|c|c|}
\hline Proses Produksi & Back Tracking (m) \\
\hline $\begin{array}{ll}- & \mathrm{D}-\mathrm{B} \\
- & \mathrm{E}-\mathrm{D} \\
- & \mathrm{F}-\mathrm{C} \\
- & \mathrm{F}-\mathrm{E} \\
- & \mathrm{G}-\mathrm{F} \\
& \mathrm{O}-\mathrm{N} \\
\end{array}$ & $\begin{array}{c}45 \\
20,6 \\
41,3 \\
10,2 \\
14,9 \\
24 \\
\end{array}$ \\
\hline Total & $156 \mathrm{~m}$ \\
\hline
\end{tabular}

Back tracking pada proses pembuatan kain CC 1088 V3/R, C 1296 V3/R, CC 5001 V6/J pada layout awal perusahaan terjadi 6 kali dengan jarak back tracking 156 meter.

\section{Perbandingan Back Tracking}

Dari hasil analisa back tracking sebelumnya dapat diketahui perbandingan seperti tabel berikut ini

\begin{tabular}{|c|c|c|}
\hline $\begin{array}{c}\text { Layout } \\
\text { Awal }\end{array}$ & $\begin{array}{c}\text { Layout } \\
\text { Usulan }\end{array}$ & Selisih \\
\hline 185 & 156 & 29 \\
\hline
\end{tabular}

\section{Analisa Perbandingan Algoritma CRAFT dengan}

\section{Algoritma MULTIPLE dan Algoritma BLOCKPLANT.}

1. Algoritma MULTIPLE

Algoritma MULTIPLE didesain untuk diterapkan pada layout banyak lantai. Algoritma Multiple dibuat berdasarkan konsep Spacefiling Curve, luas departemen yang fleksibel. Pengontrolan bentuk departemen dan proses pencarian secara Stepest Descent Heuristic. Model secara umum sama dengan CRAFT yaitu model QAP. Kemampuan untuk menangkal initial Layout Pada algoritma Multiple kurang baik sehingga untuk menghitung biaya initial layout yang sesungguhnya dapat menggunakan algoritma CRAFT karena pada programnya sudah tersedia menu matrik initial layout.

Pada PT. Eratex Djaja. LTD. Tbk Probolinggo memiiki layout dengan satu lantai, sedangkan MULTIPLE lebih efektif diterapkam layout yang memiliki lebih dari satu lantai sehingga dalam penelitian ini lebih cocok digunakan algoritma CRAFT.

\section{Algoritma BLOCKPLANT}

Algoritma BLOCKPLANT merupakan algoritma konstruksi yang berfungsi untuk membuat sebuah layout baru. Hal ini dikarenakan BLOCKPLANT mempunyai kemampuan untuk merandom dengan hanya berdasarkan pada luas departemen, sehingga layout yang dihasilkan bisa berbeda jauh dengan layout perusahaan yang sudah ada. Jika hasil layout dari BLOCKPLANT diterapkan konstruksi biaya perpindahan lebih besar.

\section{E. KESIMPULAN}

Dari perhitungan dan analisa data yang telah dilakukan, maka dapat diambil kesimpulan sebagai berikut :

1. Bentuk Tata Letak departemen Weavingyang diusulkan adalah dengan keterangan sebagai berikut 

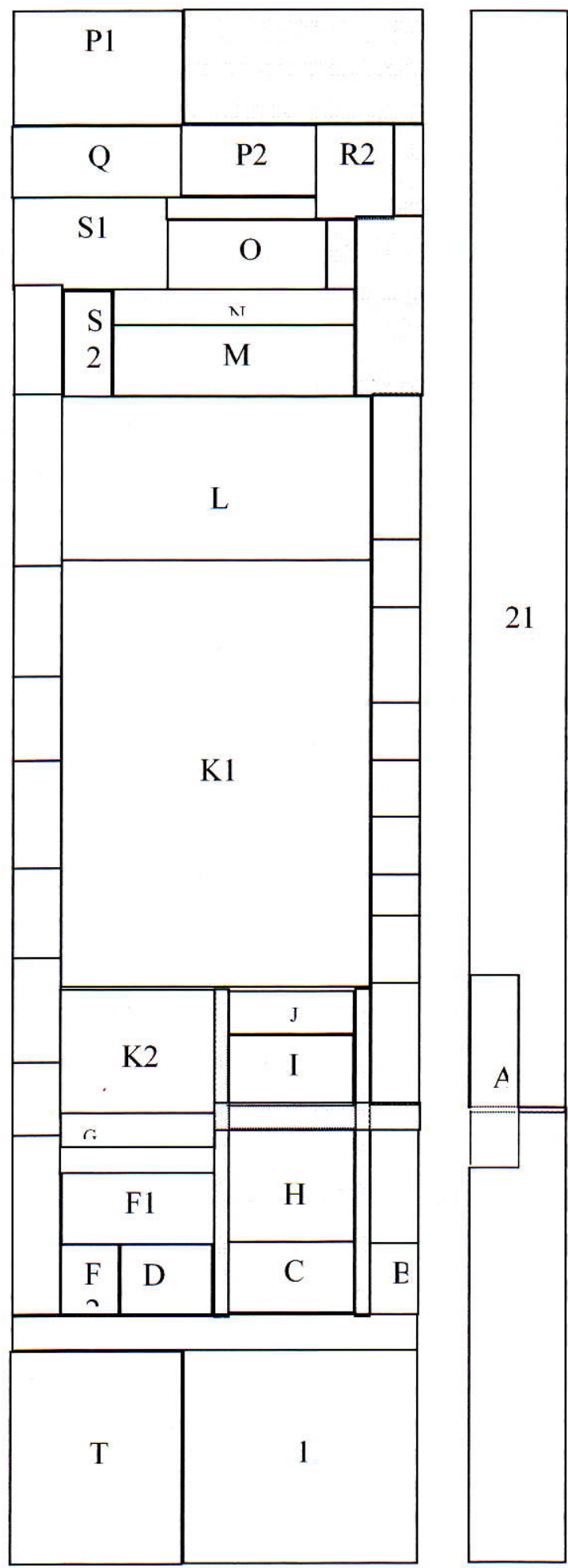

Keterangan :

A : Cone Packing.

B : Stock Beam Sizing.

C : Stock Beam Warping.

D : Sizing.

E : Stock Beam Warping.

$\mathrm{F}$ : Warping

G : Tempat Penyimpanan Benang.

H : Tempat Pencucukan.

I : Hasil Roll Pencucukan.

$\mathrm{J}$ : Cone Warping.

$\mathrm{K}$ : Penenunan

L : Penenunan.

M : Cloth Inspecting.

$\mathrm{N}$ : Folding.

O : Cloth Inspecting.

P : Tempat hasil pengecekan operator

Q : Tempat Pengepakan hasil Ball.

R : Tempat Pengepakan Hasil Roll.

$\mathrm{S}$ : tempat hasil ball dan roll.

$\mathrm{T}$ : Gudang Penyimpanan 1

: Jalan limtasan

2. Perbandingan jarak dan back tracking material handling.

- Jarak tempuh material handling pada layout awal sebesar 18354,98 meter dan pada layout usulan adalah 163692,34 meter sehingga ada pengurangan jarak tempuh sebesar 19851,64 meter. Jadi layout usulan mempunyai jarak 10,82 \% lebih pendek dibandingkan dengan layout awal.

- Terjadinya back tracking material handling pada layout awal sebanyak 6 
- Terjadinya back tracking material handling pada layout awal sebanyak 6 kali dengan jarak 185 meter dan pada layout usulan sebanyak 6 kali dengan jarak 159meter yang artinya terdapat selisih jarak back tracking sebesar 15,68 \%.

3. Besar biaya yang dikeluarkan oleh perusahaan untuk material handling pada layout awal sebesar Rp.32.782.605,49 dan pada layout usulan adalah sebesar Rp. 32.110.746,83 yang artinya terdapat selisih Rp.671.858,66. Jadi layout usualan dapat menghemat biaya material handling sebesar $10,82 \%$ per bulan.

\section{DAFTAR PUSTAKA}

Apple, James M, Tata Letak Pabrik dan Pemindahan Bahan, edisi ketiga, ITB Bandumg, 1990.

Chang, Yih Long, Quantitative System, For Operation Manajemen, New Jersey, PrenticeHall, 1989.

Franciss, Richart L. and White, John A., Facility Layout and Analitical Approach, Prentice-Hall International, 1974

Garside, Annisa Kesy, Analisa Algoritma Layout Heuristik untuk Meminimasi Total Material Handling Dalam Perencanaan Tata Letak Fasilitas, Laporan Penelitian, Fakultas Teknik Universitas Muhammadiyah Malang, 2000

Heragu, Sunderesh, Facilities Design, PWS PublishingCompany, 1997

Harsono, Manajemen Pabrik, Balai Aksara,1984 Marwan Assri dan John
Suprianto, Manajemen Perusahaan Pendekatan Operasional, edisi kesatu, BPFE Yogyakarta, 1986

Tompkins, James A, White, John A, Bozer, Yavus A, Frazelle, Edward H, Tanchocho, J.M.A, Trevino, Jaime, Facility Planning, second edition, John Wiley \& Shons Inc, 2002

Wigjosoebroto, Sritomo, Tata Letak Pabrik dan Pemindahan Bahan, edisi ketiga, Guna Widya, Jakarta, 2003

Kakiay J. Thomas, 2004, Dasar Teori Antrian Untuk Kehidupan Nyata, Andy,Yogyakarta.

Subagyo Pangestu, 1999, Dasar-Dasar Operation Research, BPFE, Yogyakarta.

Gaspersz Vincent, 1996, Analisis Sistem Terapan Berdasarkan Pendekatan Teknik Industri, Tarsito, Bandung.

Simarmata A. Dj, 1995,Operatipon Research Sebuah pengantar, PT.Gramedia, Jakarta.

Graw Hill Mc, 1998, Simulation With Arena, Boston, Massachussets Burr Ridge, Ioa Madison, Wisconsin, NewYork.

Wigjosoebroto Sritomo, 2000, Ergonomi StudiGerak dan Waktu , Guna Widya ,Jakarta.

Taha, Hamdy A , 1997, Riset Operasi SuatuPengantar, Bina Rupa Aksara, Jakarta. 
Basu Swasta, 1988, Metode Kuantitatif Untuk Manajemen, Edisi-Pertama, Liberty Yogyakarta

Buffa, Elwood S, 1985, Manajemen Operasi dan Produksi Modern, PT.Gramedia, Jakarta

Dimyati, Tjutju T, 1994, Operation Research Modelmodel Pengambilan Keputusan, Sinar Baru, Bandung

Herjanto, Eddy, 1999, Perencanaan Dan Pengendalian Produksi,

Makridakis, Spyros, 1995, Metode Dan Aplikasi Peramalan, Erlangga, Jakarta

Pangestu S, Marwan Asri dan T.Hani Handoko, 1985, Dasar-dasar Operations Research, Edisi-Kedua, BPFE UGM, Yogyakarta

Pangestu S, 1986, Forecasting Konsep dan Aplikasi, Edisi-Kedua, BPFE-UGM, Yogyakarta

Taha, Hamdy A, 1996, Riset Operasi Suatu engantar, Edisi-Kelima, Bina Rupa Aksara, Jakarta

Biegel, Jonh E, 1992, Pengendalian Produksi Suatu Pendekatan Kuantitatif, Akademika Pressindo, Jakarta

Baroto, Teguh ST, 2002, Diktat Perencanaan Dan Pengendalian Produksi by System Modelling Corporation, UMM

Napitulu, Juanda, dkk, 1997, Buku Ajar Operation Research, Cisarua, Bogor

Indriyo G, 1999, Manajemen Operasi, Edisi I, BPFE, Yogyakarta 